\title{
Facing the unexpected - A content analysis of how dyads face the challenges of postoperative heart failure
}

\author{
Maria KC Ahldén ${ }^{1,}$ Helén Rönning", Susanna Ågren ${ }^{3,4}$ \\ 1. Oslo University Hospital, Department of Acute Health Care, Department of Intensive Care, Ullevål University Hospital, \\ Oslo, Norway. 2. School of Health Sciences, Jönköping University, Jönköping, Sweden. 3. Department of Medicine and \\ Health Sciences, Linköping University, Department of Cardiothoracic Surgery, County Council of Östergötland, Linköping, \\ Sweden. 4. Department of Medicine and Health Sciences, Linköping University, Division of Nursing Sciences, Linköping \\ University, Linköping, Sweden.
}

Correspondence: Susanna Ågren. Address: Department of Cardiothoracic Surgery, Linköping University hospital, SE-581 83 Linköping, SWEDEN. Email: susanna.agren@liu.se

Received: August 23, 2013

DOI : $10.5430 /$ cns.v2n2p74
Accepted: January 24, 2014

URL: http://dx.doi.org/10.5430/cns.v2n2p74

\section{Abstract}

Objectives: The aim of this study was to identify the challenges, strategies and needs of dyads who are dealing with postoperative heart failure.

Background: An increasing number of patients with postoperative heart failure are living with their partner as primary caregiver. Heart failure is known to reduce quality of life but little is known about the strategies dyads use to cope with postoperative heart failure or what kind of support they need.

Methods: Data were collected through semi-structured dialogue guides. Content analysis was performed to derive the main themes and categories of the data.

Results: Three main themes were derived from the data; Everyday challenges, Strategies to deal with everyday challenges and Factors facilitating everyday life.

Conclusions: Dyads living with postoperative heart failure find the change in everyday life challenging, but have strategies to handle the situation and know what kind of help they need. With the right help from health care, quality of life and self-care can be improved.

\section{Key words}

Postoperative complication, Heart failure, Life-changing events, Self-care, Nursing

\section{I ntroduction}

Heart failure after cardiac surgery is associated with poor prognosis, and postoperative heart failure increases both shortand long-term mortality, especially in CABG patients ${ }^{[1]}$. The emotional health of partners to patients with heart failure has been described to be significantly ${ }^{[2-5]}$. It has been shown that patients and partners do not face the same challenges but both are affected. Social support to the patient has been proven to be beneficial with regards to survival ${ }^{[6,7]}$ and improving 
self-care ${ }^{[8]}$, adherence to therapy, and reducing time spent by health professionals caring for the patient ${ }^{[9]}$. A study by Buck ${ }^{[10]}$ on dyadic heart failure care showed that the overarching theme for dyads is sharing life by being connected to each other in different ways. When being part of a dyad in a non-independence relationship ${ }^{[11]}$, caregiving by the partner cannot be isolated analytically from self-care by the patient. Therefore, health care professionals needs to focus on both patient and partner to be able to support self-care and health related quality of life ${ }^{[2-5]}$. Improved healthcare has resulted in an ageing and increasing population that live with postoperative complications and there is a systematic under-provision of care for the elderly ${ }^{[12]}$. Every year, more than 1.5 million people undergo cardiac surgery worldwide, where coronary artery bypass graft or aortic valve replacement account for the majority of the procedures ${ }^{[12,13]}$. Of the patients undergoing cardiac surgery, as coronary artery bypass graft or aortic valve replacement approximately $10 \%$ develop postoperative heart failure ${ }^{[1]}$ which is a serious complication with high morbidity and mortality ${ }^{[1,14-18]}$. Common symptoms among patients with heart failure are congestion, fatigue and depression ${ }^{[19]}$ but the symptoms vary widely. Self-care has become an imperative in modern health care as well as individualized care ${ }^{[18,20,21]}$. More responsibility is put on the patient and his/hers social network as the average length of stay in hospitals decreases ${ }^{[22,23]}$. There are heart failure clinics to improve the health of the patients ${ }^{[24]}$, and studies have been done to identify partners' needs ${ }^{[25]}$, but there are few studies focusing on the dyad as a unit. Healthcare professionals' need today more information to be able to support the dyad as a unit to reduce morbidity among patients with postoperative heart failure. There is a need to find out how dyads experience living with postoperative heart failure in order to support self-care and improve quality of life.

To be able to extract patients' and partners' unique experiences, a qualitative approach was used. Since there is limited research and theory regarding dyads living with postoperative heart failure, conventional content analysis was chosen ${ }^{[26]}$. Content analysis allows for qualitative data to be reduced and inferences made ${ }^{[27]}$. It implies that it is not the actual content in the text but the meaning that can be extracted from the text, the inferences, which answers the question ${ }^{[28]}$. In this descriptive analysis, we have analysed the semi-structured dialogues between health professionals and dyads afflicted by postoperative heart failure to answer the research question.

\section{Method}

\subsection{Case presentation}

This qualitative study is part of a pilot study, a prospective, randomized intervention study aimed to analyse the content of the intervention dialogues. The purpose of the intervention study was to evaluate the effects of psychosocial support and education in postoperative heart failure patients and their partners regarding health, symptoms of depression and perceived control in addition to traditional treatment. The intervention group consisted of patients afflicted with postoperative heart failure and their partners. Psychosocial support was given by an interdisciplinary team consisting of a physician, a nurse and a physiotherapist. Two telephone follow up were made by a nurse aimed to address the dyad's concerns that were discussed in the first conversation. The sample of this qualitative study consists of the intervention group in the randomized study. The patient-partner dyads in both groups received standard care, as provided by hospital routines in the care of cardiac surgery patients. The patients arrived to the unit one day before surgery and received information from the thoracic surgeon, thoracic anesthetist and a nurse. After 1 week, the same nurse contacted the patients for a follow-up call. The partners were not systematically involved in the pre- and postoperative information. During the study period our institution did not have a structured follow-up program for patients and partners after cardiac surgery. The study was approved by the Regional Ethical Review Board in Linköping (Dnr M178-04), and followed the Declaration of Helsinki. The dyad received verbal and written information. The research group has for many years met both patient and partner in order to strengthen the dyad. We have tried to separate the dyad, but they often become suspicious and we have therefore chosen this approach. Both patient and partner had to provide informed consent before taking part in the study and the dialogues began. The results of the intervention study will be presented elsewhere. 


\subsection{Participant characteristics}

The definition of postoperative heart failure was based on the physician's clinical diagnosis of postoperative heart failure and the patient receiving treatment for postoperative heart failure, such as a circulatory assist device or inotropic support for $\geq 24 \mathrm{~h}$ postoperatively and a postoperative stay in the intensive care unit for $\geq 48 \mathrm{~h}$. Patients diagnosed with postoperative heart failure who lived with a partner where both understood written and spoken Swedish and who both agreed to be in the study was included. Exclusion criteria comprised $<30$ day life expectancy due to a life threatening disease.

The University Hospital in Linköping is the sole provider of cardiothoracic surgery in southeastern Sweden, serving a catchment area of approximately 1 million inhabitants. The department is the only unit in the area and it performs approximately 800 cardiac operations annually and about $10 \%$ of them suffer from heart failure postoperatively. 42 dyads completed baseline assessment and resulted in 17 in the control group and 25 in the intervention group.The sample contained of 24 dyads where the patient had postoperative heart failure. Most of the patients were men (20 men and 4 women) and most of the partners were women's ( 20 women and 4 men). The mean age of patients and partners was 70 and 67 years respectively and all had partners of opposite sex. Data were collected from May 2007 to August 2011(see Table 1).

Table 1. Demographic characteristics of patient and partner

\begin{tabular}{|c|c|c|c|c|c|c|c|}
\hline \multicolumn{5}{|c|}{ Patient } & \multicolumn{3}{|r|}{ Partner } \\
\hline $\mathrm{Nr}$ & Sex & Age & Education & Surgery & Sex & Age & Education \\
\hline 1 & M & 72 & Elementary & CABG & $\mathrm{F}$ & 64 & Secondary \\
\hline 2 & M & 68 & Elementary & CABG & $\mathrm{F}$ & 61 & Elementary \\
\hline 3 & M & 74 & University & AVR + Valve prothesis & $\mathrm{F}$ & 72 & University \\
\hline 4 & M & 76 & Secondary & CABG + Valve prothesis & $\mathrm{F}$ & 71 & Primary \\
\hline 5 & M & 82 & Elementary & CABG & $\mathrm{F}$ & 77 & Elementary \\
\hline 6 & M & 51 & Elementary & AVR + Valve prothesis & $\mathrm{F}$ & 55 & University \\
\hline 7 & M & 62 & University & CABG & $\mathrm{F}$ & 67 & Secondary \\
\hline 8 & $\mathrm{~F}$ & 74 & Elementary & CABG & M & 77 & University \\
\hline 9 & M & 80 & Elementary & Mitral annuloplasty & $\mathrm{F}$ & 77 & Elementary \\
\hline 10 & $\mathrm{~F}$ & 59 & University & CABG & M & 59 & Secondary \\
\hline 11 & M & 53 & Elementary & AVR & $\mathrm{F}$ & 61 & Primary \\
\hline 12 & M & 60 & Primary & CABG & $\mathrm{F}$ & 62 & Secondary \\
\hline 13 & M & 57 & Secondary & CABG & $\mathrm{F}$ & 57 & Secondary \\
\hline 14 & M & 71 & Secondary & CABG & $\mathrm{F}$ & 61 & University \\
\hline 15 & $\mathrm{~F}$ & 63 & Elementary & CABG & $\mathrm{M}$ & 63 & Elementary \\
\hline 16 & M & 74 & University & CABG & $\mathrm{F}$ & 65 & University \\
\hline 17 & M & 79 & Secondary & $\mathrm{CABG}$ & $\mathrm{F}$ & 78 & Elementary \\
\hline 18 & M & 87 & Elementary & $\mathrm{CABG}+\mathrm{AVR}$ & $\mathrm{F}$ & 74 & Secondary \\
\hline 19 & M & 78 & Primary & AVR & $\mathrm{F}$ & 72 & University \\
\hline 20 & M & 79 & Elementary & CABG & $\mathrm{F}$ & 78 & Elementary \\
\hline 21 & M & 57 & Secondary & $\mathrm{AVR}+\mathrm{MVR}$ & $\mathrm{F}$ & 57 & Secondary \\
\hline 22 & $\mathrm{~F}$ & 66 & Secondary & CABG & M & 66 & Secondary \\
\hline 23 & M & 76 & University & CABG & $\mathrm{F}$ & 65 & University \\
\hline 24 & M & 63 & Elementary & $\mathrm{AVR}+\mathrm{MVR}$ & $\mathrm{F}$ & 63 & Elementary \\
\hline
\end{tabular}




\subsection{Procedure}

In the intervention group, the patient-partner received conventional care, and in addition psycho educational support from an interdisciplinary team consisting of a physician, nurse and physiotherapist in order to provide patient-partner with the opportunity to process their experiences in the context of cardiac surgery and rehabilitation. Information and advice was also provided to the patient and partner to help them handle the rehabilitation phase. Data were collected at three occasions. The first took place 4-6 weeks after discharge when the dyad met the interdisciplinary team consisting of a physician, a registered nurse and a physiotherapist from the thoracic intensive care unit. The meeting took place at the hospital and lasted up to two hours. Each profession used a semi-structured dialogue guide, specialized to their area of expertise, and the nurse recorded the dialogues in writing. These dialogues were not initially meant to be analysed, therefore they were not audio-recorded, but the research team found the results to be rich and interesting enough to present them. The guides focused on the dyads' questions, concerns about their situation and individual goals. The dyads were encouraged to speak freely, but follow-up questions were used to clarify statements. The dialogue guides were developed by the interdisciplinary team, based on current literature and the results of a previous study ${ }^{[25]}$ (See Figure 1).

Figure 1. Dialogue guides

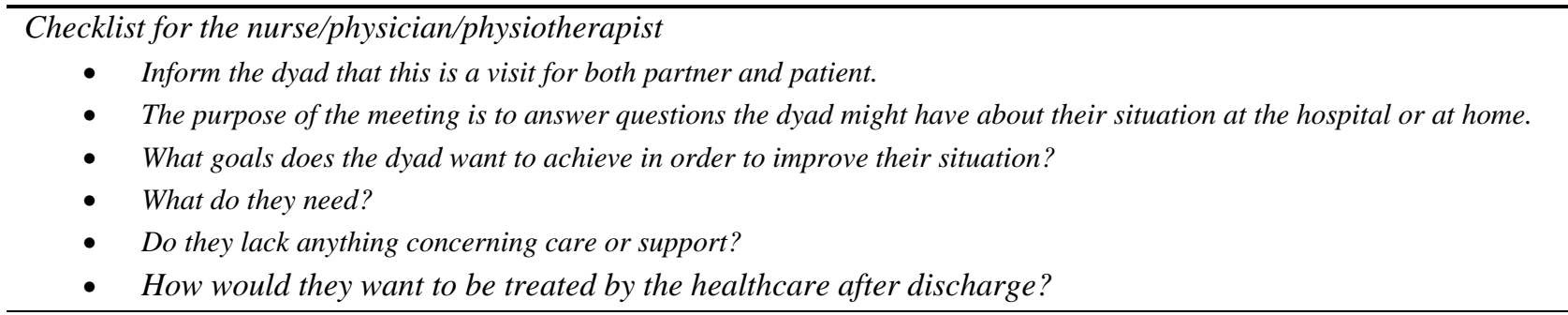

\begin{tabular}{|c|c|c|c|}
\hline \multicolumn{4}{|l|}{ Nurse } \\
\hline Wellbeing & $\begin{array}{l}\text { How is patient/partner } \\
\text { doing? }\end{array}$ & $\begin{array}{l}\text { What memories does patient/partner } \\
\text { have from the thoracic intensive } \\
\text { care unit? Unpleasant/unreal } \\
\text { experiences, dreams/nightmares? }\end{array}$ & $\begin{array}{l}\text { Do the patient/partner feel anxiety } \\
\text { or low-spirited? }\end{array}$ \\
\hline $\begin{array}{l}\text { During the thoracic } \\
\text { intensive care unit }\end{array}$ & $\begin{array}{l}\text { How was sleep at the } \\
\text { thoracic intensive care unit } \\
\text { and how is it now? Are } \\
\text { sleeping pills being used? }\end{array}$ & $\begin{array}{l}\text { Has the patient/partner felt safe } \\
\text { during the period they spent at the } \\
\text { thoracic intensive care unit? }\end{array}$ & $\begin{array}{l}\text { The patient/partner gives their } \\
\text { overall impression of the thoracic } \\
\text { intensive care unit and can suggest } \\
\text { improvement. }\end{array}$ \\
\hline Present time & $\begin{array}{l}\text { How does it work at home, } \\
\text { practically and emotionally? }\end{array}$ & $\begin{array}{l}\text { Has the patient/partner changed the } \\
\text { way they live? Is patient or partner } \\
\text { on sick leave? }\end{array}$ & $\begin{array}{l}\text { The dyad is offered a visit to the } \\
\text { thoracic intensive care unit. }\end{array}$ \\
\hline \multicolumn{4}{|c|}{ Physiotherapist } \\
\hline \multicolumn{4}{|c|}{$\begin{array}{l}\text { Testing of muscle function } \\
\text { Physical capacity }\end{array}$} \\
\hline \multicolumn{4}{|l|}{ Physician } \\
\hline
\end{tabular}

- Information and advice is given to ease rehabilitation.

- Additional follow-up with the nurse via phone is offered.

Follow up by phone calls were made by the nurse 10-12 weeks and 22-24 weeks after discharge from hospital and individual dialogues were held with both patient and partner. During these calls, the nurse used the dialogue guide as well as notes to be able to reconnect to previous dialogue. Each dialogue lasted up to one hour and was recorded in writing by the nurse. The first four telephone follow up with dyads were not recorded in writing. Since the content of these phone calls were considered to give depth and greater understanding to the situation of the dyads, it became recorded in writing. 


\subsection{Analysis}

Hsieh's and Shannon's ${ }^{[26]}$ approach to conventional content analysis was used as a foundation for the analysis. The texts were initially read several times to obtain a sense of the whole. Texts were then read carefully word for word and by highlighting words that appeared to capture key concepts, preliminary codes were derived. If data could fit more than one code, codes were revised. As the text was condensed, codes were merged into subcategories that were reflective of more than one thought. Next, subcategories were organized into clusters according to their content and categories were formulated. Continuous movement between the whole and the parts of the text took place during the analysis process and formulated the themes from the underlying meaning of the categories. The nurse then read the study findings. Discrepancies were reviewed and discussed until consensus was reached in the final coding of the data.

\section{Results}

The findings has been analysed from the three occasions the dyads had contact with the team and revealed three themes; Everyday challenges, Strategies to deal with everyday challenges and Factors facilitating everyday life. Quotes are extracted from the written recordings made by the nurse.

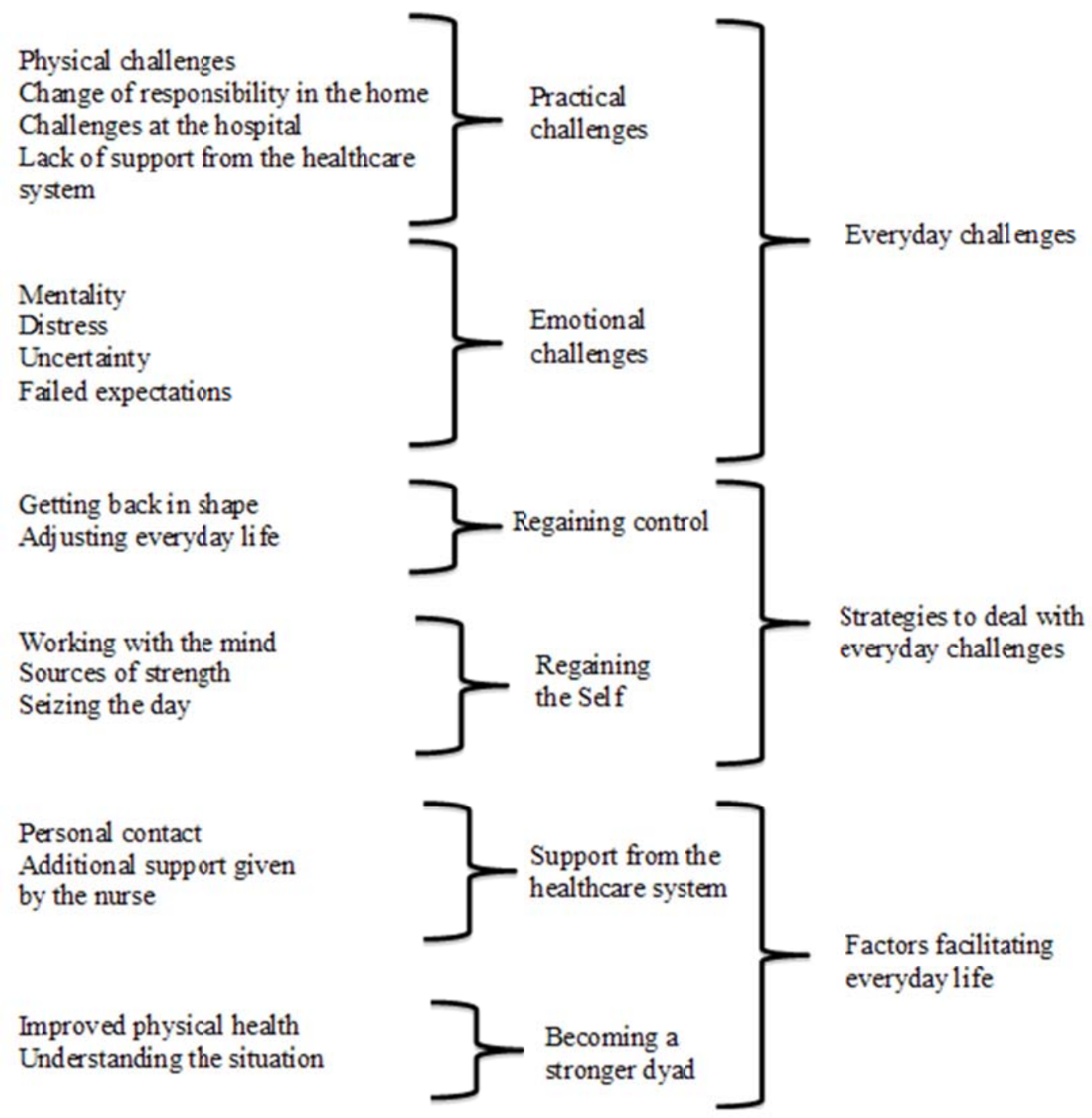

Figure 2. Dendrogram showing the result of analysis 


\subsection{Everyday challenges}

Changes in normality provided challenges that encompassed body, mind and environment.

\subsubsection{Practical challenges}

Physical challenges - Dyads found breathlessness and coughing to be obstructive to everyday life, making walks and conversations difficult. Valued activities became difficult and dyads regretted not being able to do it anymore. Poor appetite and limited physical activity resulted in weight loss and loss of muscle. Being unfit and suffering from weak muscles was a hindrance. Tiredness limited the everyday and motivation was hard to muster. "There are fewer spontaneous whims since his energy lasts only for the everyday life and planned trips." Lack of sleep and an increased need for sleep during rehabilitation resulted in a patients needing to take naps during the day.

Change of responsibility in the home - Several partners experienced an increased level of responsibility for the patients' everyday life with regards to the diet, medication or activity. "It wasn't like that before, before we were equals." Housekeeping was managed by the partner alone and the change was perceived as difficult for both parts of the dyad. "It's hard not being capable", "I feel helpless when I'm not in control".

Challenges at the hospital - Patients expressed that noise during night-time, difficulty to get attention from the personnel or disturbing patients close by were challenges in connection to their hospital stay. Partners instead felt helpless when they wanted to help but felt like they were in the way.

Lack of support from the health care system - Follow-ups where in some cases performed a long time after discharge, sometimes not at all due to a shortage of physicians. "It's lonely after the discharge, there's no natural contact". Meeting a different physician every time created a feeling of insecurity and dyads missed continuity. One dyad expressed disappointment that the patient's worsening symptoms had not been taken seriously when she later had another heart attack. "It's hard not to be believed". Dyads felt abandoned by the healthcare system when there was no time for them. Both partners and patients expressed feelings of being left out and almost giving up.

\subsubsection{Emotional challenges}

Mentality - Poorer memory and ability to concentrate was frustrating for dyads. Both partners and patients spoke of a reduced capacity to handle setbacks. Feeling low "I feel so sad when I think about death and how close it is" and the feeling of being mentally exhausted had a negative influence on the everyday life. Several dyads had not talked to each other about the severity of the illness or death and that caused feelings of loneliness.

Partners expressed anxiety when the patient was delirious and wondered whether the patient would ever be the same again. One patient who had suffered delusions questioned whether he was normal at the time of the dialogue.

Feelings of injustice, being punished and unpreparedness were expressed, as was the feeling of unreality "I didn't want to believe that I was sick at first.", "Did it really happen?".

Distress - Partners were distressed by the feeling that they needed to be in control. One partner said she "...need to be in total control, cannot get sick." This increased sense of responsibility and the distress it lead to prevented several dyads from traveling.

Uncertainty - Not knowing was a great challenge to the dyads. Worrying about setbacks, the future and the health of both partner and patient caused a constant anxiety for many dyads. "It's like a knot in my stomach", "You're never really sure."

Only one dyad verbalized that they did not get enough information at discharge, but most dyads had questions about diet, activity, the treatment and alternatives at the follow-up of the intervention. 
Failed expectations - Only one patient believed that he would become completely healthy after the surgery, but many patients expressed disappointment when they did not return to their former strength "Life is different after the surgery". Disappointment was expressed when dyads were not able to do what they had planned.

\subsection{Strategies to deal with everyday challenges}

Dyads were forced to face the changes postoperative heart failure brought and had different strategies for dealing with the challenge.

\subsubsection{Regaining control}

Getting back in shape - Many dyads faced the challenge of weak muscles by setting up goals and exercising together. Some goals were general, such as having energy to manage everyday life. Others had more specific aims, for example traveling to Spain or do a Vasalopp (90 km on cross-country skis).

Adjusting everyday life - Many dyads faced the new challenges by adjusting to them. One dyad found it stressful that so many friends wanted to talk to them while playing golf, so they went to the golf course at times when very few others were there. Both partners and patients learned how to say no and step down from official commitments or work.

\subsubsection{Regaining the self}

Working with the mind - To handle the emotional challenges, dyads had different goals. One patient aimed to scale down on anti-depressive agents and others aimed to go back to work. "I'm working with my mind to be able to move on in life."

Sources of strength - Work as well as vacations were important sources of strength. One patient started singing in a choir again, expressing the importance of social life. Exercising or resting were other ways to gain strength. Both patients and partners used the word "holy" to describe the importance of their private time. Dyads that discussed the situation found strength in each other. Both partners and patients talked to family, friends or colleagues about the challenges. A few used the option to talk to a welfare officer.

Seizing the day - Trying to live day by day and not ponder too much was a strategy for several dyads and looking forward to or having expectations on the future was bordered by a raised level of observation. Both partners and patients expressed gratitude and enjoyed things like being able to go to a restaurant. One dyad got married in spite of decreasing health and three dyads went traveling. One dyad expressed the importance of taking care of life, the life partner and being humble to life.

\subsection{Factors facilitating everyday life}

Through help from the healthcare system, the dyads' everyday was facilitated.

\subsubsection{Support from the health care system}

Personal contact - To be well treated by health care personnel was very important for the dyads to get through the tough situation. Partners and patients could relax and felt they were cared. Partners felt safer when they could be close to the patient. "I'm safer when I can be with [name of patient]. I'm more worried when I'm at home and have to call to get some information".

Additional support given by the research nurse - The support given during the intervention mainly consisted of advice on who to ask for help or what to ask regarding a certain problem and was appreciated by the dyads as helpful.

\subsubsection{Becoming a stronger dyad}

Improved physical health - With time patients could help out more at home and the burden on the partner eased. A decreased need to check on the other and less intense nightmares improved sleep, exercise improved fitness and some 
patients felt they were back in shape and healthy again after the surgery. "The strength returns day by day." Several patients also reported a better appetite.

Understanding the situation - Information from the thoracic intensive care unit was appreciated as was the call from the surgeon to the partner directly after the surgery. Two partners expressed considerably less stress the second time the patient had to undergo percutaneous coronary intervention compared to the first time, when they had been close to panic. The dyads that had a diary found this very helpful when trying to understand and obtain a sense of context. The heart course taken by some patients (not available for partners) was also helpful. To understand that they would not become stronger or healthier helped patients accept the situation. Follow-ups were important to the dyads in that they understood the seriousness of the condition and realized just how sick the patient had been.

\section{Discussion}

\subsection{Findings}

The main findings of this report are that dyads affected by postoperative heart failure are challenged by the change in normalcy but have goals in their everyday challenges concerning their health and ideas on how to reach these. Information and understanding together with continuous support from health care services was expressed as being the most pressing need of the dyads.

Dyads struggled with a change of responsibility, reduced physical capacity and a reduced capacity to handle stressful situations. Similar findings have been described in earlier studies of patients with chronic heart failure ${ }^{[29,30]}$, and indicates that these groups face similar challenges. What this study adds is the feeling of disappointment when rehabilitation did not have the expected effect and the dyad had to accept that life wasn't going to get back to normal again. The study also reveals how the challenges due to postoperative heart failure not only affected the patient or the partner, but the dyad as a unit. Both patient and partner were limited and had to adjust to a new way of living.

In our study, dyads described different strategies to cope with an everyday limited by postoperative heart failure, coherent with the patients in Falk's study ${ }^{[30]}$ where patients with HF adjusted the everyday activities depending on how much energy the patient had. The dyads in our study had joint goals and they worked together to reach them, some taking their own initiatives when health care didn't have more to offer. Our study also demonstrates how dyads used seizing the day as a management strategy, being grateful for the chances given. Vacation trips, planning for the future and worrying less were signs of mastery.

Dyads, who view a cardiac event as a positive experience, find it easier to overcome possible resentments within the relationship and come up with innovative ways to deal with the situation ${ }^{[6]}$. In order to cope with the situation, understanding was very important and so was a continuous contact with the health care.

The dyads in the intervention group all had questions during their follow-up, suggesting that they hadn't understood the situation or how to handle it. What dyads in our study expressed, was direct wishes on what kind of help they needed. What dyads wanted was more information during hospitalization and better follow-up after, both from the physician and physiotherapist.

Strengthening the dyad with knowledge and support can facilitate the process of learning how to live with postoperative heart failure and that way, improve health related quality of life of the dyad. Life changed unexpectedly after the surgery and did not return to what it had been, but all dyads tried to restore some kind of quality in life. By finding out what the goals and needs of dyads living with postoperative heart failure are, suitable help or support can be given and this might increase the dyad's capacity of self-care. 


\subsection{Reliability}

To ensure credibility using the criteria of Lincoln and Guba ${ }^{[31]}$, data were collected by the same team, using the same semi-structured dialogue guide in every meeting. The dialogue guide was tested in a pilot sample of four dyads. The notes from all dialogues were analysed by the first author and checked for dependability by the nurse in the interdisciplinary team and the study supervisor. Using quotations and examples from the dyads to illustrate the findings helps the reader to judge the situations, thereby enhancing the transferability of the findings.

\subsection{Limitations}

The results have to be interpreted cautiously and need be confirmed in other studies as this was planned to be a pilot study, with all its limitations. However, the findings of this study provide information that can serve as basis for future more extensive and systematic studies of these dyads.

Other limitations are that written notes of the dialogues were used instead of audio-recorded and transcribed manuscripts, which might have had an effect on the result. Since one challenge presented by conventional content analysis is failure to develop a complete understanding of the context ${ }^{[24]}$, the research nurse's long experience working in the thoracic intensive care unit was considered an advantage. The first author had no similar experience so copies of the medical files were read to prevent misunderstanding the context. That way, the risk to compromise dependability due to the written script instead of an audio-recorded and transcribed script was reduced.

\subsection{Conclusions}

What this paper adds are the experiences of postoperative heart failure from the dyad's perspective. This study provides a better understanding of the challenges postoperative heart failure presents and the strategies used for coping with the situation. The postoperative complication makes earlier expectations of rehabilitation inaccurate and returning to "normal" is not possible. Furthermore, it shows how healthcare can facilitate the transition process. By helping the dyad understand the situation, the healthcare system can support the dyad to become stronger and facilitate the transition to everyday life and a restored quality of life.

\section{Acknowledgment}

We thank Linköping University, the National Association of Heart and Lung diseases for financial support. We also thank the partners and the postoperative heart failure patients who participated in the study, Helene Nyberg, Sören Berg, Anette Brostedt who participated in the intervention, the administrators at the Department of Medical and Health Sciences Division of Nursing Sciences Linköping for support with language review, Linköping University and Department of Cardiothoracic Surgery, Linköping University Hospital.

\section{References}

[1] Vanky FB, Hakanson E, Svedjeholm R. Long-term consequences of postoperative heart failure after surgery for aortic stenosis compared with coronary surgery. Ann Thorac Surg. 2007 Jun; 83(6): 2036-43. PMid:17532392 http://dx.doi.org/10.1016/j.athoracsur.2007.01.031

[2] Trivedi RB PJ, Fihn SD, Edelman D. Examining the interrelatedness of patient and spousal stress in heart failure: conceptual model and pilot data. J Cardiovasc Nurs. 2012; 27(1): 24-32. http://dx.doi.org/10.1097/JCN.0b013e3182129ce7

[3] Lee J PS, Feeney K. Emotional Distress and Cognitive Functioning of Older Couples: A Dyadic Analysis. Journal of Aging and Health 2012; 24(1): 113-40. http://dx.doi.org/10.1177/0898264311423703

[4] Rohrbaugh MJ SV, Cleary AA, Berman JS, Ewy GA. Health consequenses of partner distress in cou-ples coping with heart failure. Heart \& Lung. 2009; 38: 298-305. http://dx.doi.org/10.1016/j.hrtlng.2008.10.008

[5] Chung ML MD, Lennie TA, Rayens MK. The effects of deperssive symptoms and anxiety on quality of life in patients with heart failure and their spouses: testing dyadic dynamics using actor-partner interdependence model. J Psychosom Res 2009;67:29-35. http://dx.doi.org/10.1016/j.jpsychores.2009.01.009 
[6] Rohrbaugh MJ SV, Coyne JC. Effect of marital quality on eight-year survival of patients with heart failure. Am J Cardiol. 2006; 98:1069-72. http://dx.doi.org/10.1016/j.amjcard.2006.05.034

[7] King KB RH. Marriage and long-term survival after coronary artery bypass grafting. Health psychology. 2012; 31(1): 55-62. PMid:21859213 http://dx.doi.org/10.1037/a0025061

[8] Gallagher R LM, Jaarsma T. Social support and self-care in heart failure. J Cardiovasc Nurs. 2011; 26(6): 439-45. PMid:21372734 http://dx.doi.org/10.1097/JCN.0b013e31820984e1

[9] World Health Organization. Adherence to long-term therapies: evidence for action. 2013 [cited 2014 January 10]. Available from: http://whqlibdoc.who.int/publications/2003/9241545992.pdf.

[10] Buck HG KL, Hupcey JE. Dyadic heart failure care types: qualitative evidence for a novel typology. J Cardiovasc Nurs. 2013. PMid:23388704 http://dx.doi.org/10.1097/JCN.0b013e31827fcc4c

[11] Kenny DA KD, Cook WL. Dyadic Data Analysis: New York, NY:Guilford Press; 2006.

[12] Bridgewater B GJ, Walton P, Kinsman R. EACTS Adult Cardiac Surgical Database Report. . 4th ed. ed: Henley-on-Thames, Oxfordshire: Dendrite clinical systems; 2010.

[13] The society of Thoracic Surgeons. Adult Cardiac Surgery Database, Executive Summary 10 Years, STS Report - Period Ending 09/30/2011. 2011 [cited 2014 January 10]. Available from: http://www.sts.org/sites/default/files/documents/2012\%20-\%20Adult\%20-\%204thHarvestExecutiveSummary.pdf

[14] Surgenor SD OCG, Lahey SJ, Quinn R, Charlesworth DC, Dacey LJ, Clough RA, Leavitt BJ, Defoe GR, Fillinger M, Nugent WC. Predicting the Risk of Death from Heart Failure After Coronary Artery Bypass Graft Surgery. Anesth Analg. 2001; 92(3): 596-601. PMid:11226084 http://dx.doi.org/10.1213/00000539-200103000-00008

[15] Vanky FB, Hakanson E, Tamas E, Svedjeholm R. Risk factors for postoperative heart failure in patients operated on for aortic stenosis. Ann Thorac Surg. 2006 Apr;81(4):1297-304. PubMed PMID: 16564261. Epub 2006/03/28. eng.

[16] Smith DH JE, Thorp ML, Yang X, Petrik A, Platt RW, Crispell K. Predicting poor outcomes in heart failure. Perm J 2011;15(4):4-11.

[17] McMurray JJ AS, Anker SD, Auricchio A, Böhm M, Dickstein K, Falk V, Filippatos G, Fonseca C, Gomez-Sanchez MA, Jaarsma T, Köber L, Lip GYH, Maggioni AP, Parkhomenko A, Pieske BM, Popescu BA, Rönnevik PK, Rutten FH, Schwitter J, Seferovic P, Stepinska J, Trindade PT, Voors AA, Zannad F, Zeiher A. . ESC Guidelines for the diagnosis and treatment of acute and chronic heart failure 2012. Eur Heart J. 2012; 14: 803-69. http://dx.doi.org/10.1093/eurjhf/hfs105

[18] McDonagh TA BL, Clark AL, Dahlström U, Ekman I, Lainscak M, McDonald K, Ryder M, Strömberg A, Jaarsma T, on behalf of Heart Failure Association committee on patient care. European Society of Cardiology Heart Failure Association. Standards for delivering heart failure care. Eur J Heart Fail. 2011; 13: 235-41. http://dx.doi.org/10.1093/eurjhf/hfq221

[19] heartfailuresmatters.org. Symptoms of heart failure [cited 2014 January 10]. Available from: http://www.heartfailurematters.org/EN/Understanding-heart-failure/Symptoms-of-heart-failure.

[20] Riegel B DV, Hoke L, McMahon JP, Reis BF, Sayers S. A motivational counseling approach to im-proving heart failure self-care - mechanisms of effectiveness. J Cardiovasc Nurs. 2006; 21(3): 232-41. http://dx.doi.org/10.1097/00005082-200605000-00012

[21] Riegel B MD, Anker SD, Appel LJ, Dunbar SB, Grady KL, Gurvitz MZ, Havranek EP, Lee CS, Linden-feld J, Peterson PN, Pressler SJ, Schocken DD, Whellan DJ; on behalf of the American Heart Association council on cardiovascular nursing, council on clinical cardiology, council on nutrition, physical activity, and metabolism, and interdisciplinary council on quality of care and outcomes research. . Promoting self-care in persons with heart failure - a scientific statement from the American Heart Association. . Circulation. 2009; 120: 1141-63. http://dx.doi.org/10.1161/CIRCULATIONAHA.109.192628

[22] Mejhert M PH, Edner M, Kahan T. . Epidemiology of heart failure in Sweden - a national survey. . Eur J Heart Fail. 2001; 3(1): 97-103. http://dx.doi.org/10.1016/S1388-9842(00)00115-X

[23] OECD. Health at a glance 2011 [cited 2014 January 10]. Available from: doi: 10.1787/health_glance-2011-en http://dx.doi.org/10.1787/health_glance-2011-en

[24] Strömberg A MJ, Fridlund B, Leving LÅ, Karlsson JE, Dahlström U. Nurse-led heart failure clinics improve survival and self-care behaviour in patients with heart failure - Results from a prospective, random-ised trial. Eur Heart J. 2003; 24:1014-23. http://dx.doi.org/10.1016/S0195-668X(03)00112-X

[25] Agren S, Frisman GH, Berg S, Svedjeholm R, Stromberg A. Addressing spouses' unique needs after cardiac surgery when recovery is complicated by heart failure. Heart Lung. 2009 Jul-Aug;38(4):284-91. PubMed PMID: 19577699. Epub 2009/07/07. eng.

[26] Shieh HF SS. Three approaches to Qualitative Content Analysis. Qual Health Res. 2005; 15: 1277-88. PMid:16204405 http://dx.doi.org/10.1177/1049732305276687

[27] Patton M. Qualitative research \& evaluation methods. . 3rd ed. ed: London: Sage Publications; 2002.

[28] Krippendorff K. Content analysis: an introduction to its methodology. 2nd ed. ed: London: Sage Publications; 2004.

[29] Aldred H GM, Gariballa S. Advanced heart failure: impact on older patients and informal carers. . J Adv Nurs. 2005; 49 (2):116-24. PMid:15641944 http://dx.doi.org/10.1111/j.1365-2648.2004.03271.x

[30] Falk S WA, Lidell E. Keeping the maintenance of daily life in spite of chronic heart failure. A qualitative study. Eur J Cardiovasc Nurs. 2007;6:192-9. http://dx.doi.org/10.1016/j.ejcnurse.2006.09.002

[31] Lincoln YS GE. Naturalistic inquiry: Bevery Hills, CA: Sage Publications; 1985. 